EGU2020-2979

https://doi.org/10.5194/egusphere-egu2020-2979

EGU General Assembly 2020

(c) Author(s) 2021. This work is distributed under

the Creative Commons Attribution 4.0 License.

\title{
Characteristics of natural radiation background at the Callio Lab (Finland) performed within the BSUIN project
}

\author{
Jan Kisiel ${ }^{1}$, Kinga Polaczek-Grelik ${ }^{1}$, Katarzyna Szkliniarz ${ }^{1}$, Agata Walencik-Łata ${ }^{1}$, Jari Joutsenvaara ${ }^{2}$, \\ Hannah Puputti ${ }^{2}$, Marko Holma², and Timo Enquist ${ }^{2}$ \\ ${ }^{1}$ University of Silesia, Institute of Physics, Katowice, Poland (jan.kisiel@us.edu.pl) \\ ${ }^{2}$ University of Oulu, Finland
}

The BSUIN (Baltic Sea Underground Innovation Network) aims to enhance the accessibility of the underground laboratories in the Baltic Sea region for innovation, business and science. One of the BSUIN project activities is characterization of natural background radiation (NBR) in underground facilities. In this talk results from NBR measurements performed in Callio Lab, Pyhäsalmi, Finland, at the depth of $4100 \mathrm{~m}$ w.e. will be presented. The in-situ gamma spectra were collected with the use of HPGe semiconductor spectrometer, whereas the concentration of radon were measured with RAD7 electronic detector. In addition, the water and rock samples were taken for laboratory analysis in Institute of Physics, University of Silesia, Poland. The concentration radioisotopes in water samples were performed by using a liquid scintillation $\alpha / \beta$ counter (LSC) and a-particle spectrometry, while the concentration of radioisotopes in rock samples were performed by using laboratory gamma ray spectrometry and also a-particle spectrometry. 